Nutritional Management of Diabetes Mellitus and Dysmetabolic Syndrome 

Nestlé Nutrition Workshop Series

Clinical \& Performance Program, Vol. 11

\section{Nutritional Management of Diabetes Mellitus and Dysmetabolic Syndrome}

Editors

J.P. Bantle, Minneapolis, MN, USA

G. Slama, Paris, France

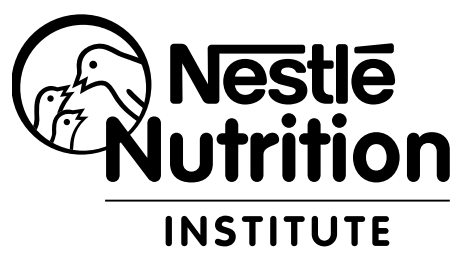




\section{Nestec Ltd., 55 Avenue Nestlé, CH-1800 Vevey (Switzerland) S. Karger AG, P.O. Box, CH-4009 Basel (Switzerland) www.karger.com}

(C) 2006 Nestec Ltd., Vevey (Switzerland) and S. Karger AG, Basel (Switzerland). All rights reserved. This book is protected by copyright. No part of it may be reproduced, stored in a retrieval system, or transmitted, in any form or by any means, electronic, mechanical, photocopying, or recording, or otherwise, without the written permission of the publisher.

Printed in Switzerland on acid-free paper by Reinhardt Druck, Basel

ISSN 1422-7584

ISBN-10: 3-8055-8095-9

ISBN-13: 978-3-8055-8095-3

\section{Library of Congress Cataloging-in-Publication Data}

Nutritional management of diabetes mellitus and dysmetabolic syndrome / editors, J.P. Bantle, G. Slama.

p. ; cm. - (Nestlé Nutrition Workshop series. Clinical \& performance program ; v. 11)

Includes bibliographical references and index.

ISBN 3-8055-8095-9 (hard cover : alk. paper)

1. Diabetes mellitus-Diet therapy. 2. Diabetes mellitus-Nutritional aspects. 3. Metabolic syndrome-Diet therapy. 4. Metabolic syndrome -Nutritional aspects. I. Bantle, John P., 1947- . II. Slama, G.

III. Nestlé Nutrition Institute. IV. Series: Nestlé Nutrition workshop series. Clinical \& performance programme ; v. 11.

[DNLM: 1. Diabetes Mellitus-diet therapy. 2. Metabolic Syndrome X-diet therapy. W1 NE228C v.11 2006 / WK 818 N9769 2006] RC662.N893 2006

616.4'620654-dc22

The material contained in this volume was submitted as previously unpublished material, except in the instances in which credit has been given to the source from which some of the illustrative material was derived.

Great care has been taken to maintain the accuracy of the information contained in the volume. However, neither Nestec Ltd. nor S. Karger AG can be held responsible for errors or for any consequences arising from the use of the information contained herein. 


\section{Contents}

\section{Foreword}

XI Contributors

The Dysmetabolic Syndrome

1 The Dysmetabolic Syndrome: Epidemiology and Etiology

Sauerwein, H.P. (The Netherlands)

15 Traditional Chinese Medicine in the Treatment of Diabetes Zhao, H.-L.; Tong, P.C.Y.; Chan, J.C.N. (Hong Kong, SAR, China)

31 Pharmacological and Surgical Intervention for the Prevention of Diabetes

Chiasson, J.-L. (Canada)

Glycemic Effect of Carbohydrates

43 The Glycemic Index: Methodology and Use

Kendall, C.W.C.; Augustin, L.S.A.; Emam, A.; Josse, A.R.; Saxena, N.; Jenkins, D.J.A. (Canada)

57 The Argument against Glycemic Index: What Are the Other Options?

Franz, M.J. (USA)

73 Low Glycemic Index Foods Should Play a Role in Improving Overall Glycemic Control in Type-1 and Type-2 Diabetic Patients and, More Specifically, in Correcting Excessive Postprandial Hyperglycemia

Slama, G.; Elgrably, F.; Kabir, M.; Rizkalla, S. (France) 
83 Is Fructose the Optimal Low Glycemic Index Sweetener? Bantle, J.P. (USA)

Beyond Glycemic Control

97 Optimal Diet for Glycemia and Lipids

Knowler, W.C. (USA)

107 Antioxidants and Diabetes

Mooradian, A.D. (USA)

127 Dietary and Body Weight Control: Therapeutic Education, Motivational Interviewing and Cognitive-Behavioral Approaches for Long-Term Weight Loss Maintenance Golay, A. (Switzerland)

Diabetes in the Life Cycle

139 The Accelerator Hypothesis: A Unifying Explanation for Type-1 and Type-2 Diabetes

Wilkin, T.J. (United Kingdom)

155 Diet and Medical Therapy in the Optimal Management of Gestational Diabetes Mellitus

Metzger, B.E. (USA)

171 Do Meal Replacement Drinks Have a Role in

Diabetes Management?

Ditschuneit, H.H. (Germany)

The Role of Drugs and Diet Therapy - Alone and Together

183 Physical Activity in Prevention and Management of Obesity and Type-2 Diabetes

Hill, J.O.; Stuht, J.; Wyatt, H.R.; Regensteiner, J.G. (USA)

197 The Role of Lifestyle Modification in Dysmetabolic Syndrome Management

Foreyt, J.P. (USA)

207 Critical Review of the International Guidelines:

What Is Agreed upon - What Is Not?

Katsilambros, N.; Liatis, S.; Makrilakis, K. (Greece)

219 Subject Index 


\section{Foreword}

Globally, the number of persons with diabetes and at risk of diabetes and cardiovascular disease is reaching epidemic proportions. Over the next decade the number is expected to grow by $25 \%$, largely driven by the rising prevalence of obesity and inactivity. The World Health Organization (WHO) estimates that 200 million persons worldwide will have diabetes by 2010 , and that number will reach 330 million by 2025. The problem is especially serious in Asia where there are 90 million people with diabetes. This includes four of the world's five largest populations with diabetes: India, 33 million people with diabetes; China, 23 million; Pakistan, 9 million, and Japan, 7 million. The WHO predicts that in less than a decade, $60 \%$ of the worldwide population with diabetes will be in Asia.

It is with these facts in mind that Nestlé Nutrition chose the topic 'Nutritional Management of Diabetes Mellitus and the Dysmetabolic Syndrome' for the 11th Nestlé Nutrition Clinical and Performance Program Workshop Series, and the site, Hangzhou, China. Unless action is taken to change the predicted path of diabetes, the disease will become a huge economic burden - both from direct healthcare costs and indirect costs due to a decline in workplace productivity, as well as losses due to premature morbidity and mortality. Therefore, individuals at risk of diabetes must be identified, and prevention and suitable treatment interventions implemented.

With Nestlé Nutrition's interest in nutrition, and the superb expertise of our chairmen, Prof. John Bantle and Prof. Gerard Slama, a program was developed highlighting the scientific evidence examining the impact of lifestyle, which includes both nutritional management and physical activity, in the prevention and treatment of diabetes. Although the optimal diet for diabetes has not yet been defined, because the optimal study has not yet been done, there is general agreement that the nutritional recommendations of the various international diabetes organizations are reasonable. There was also general agreement that nutrition and lifestyle management must be individualized for each person to enhance the potential for a successful outcome. 


\section{Foreword}

We thank our superb chairmen, our expert speakers, and especially our hosts from Nestlé China, specifically KeLan Liu and Kelly Gao and their team, for their wonderful organization and attention to so many logistical details. It is due to their efforts that participants from around the globe were able to participate in a stimulating workshop and some wonderful Chinese culture.

Patricia S. Anthony, MS, RD

Manager, Clinical Services

HealthCare Nutrition

Nestec Ltd., Vevey, Switzerland 


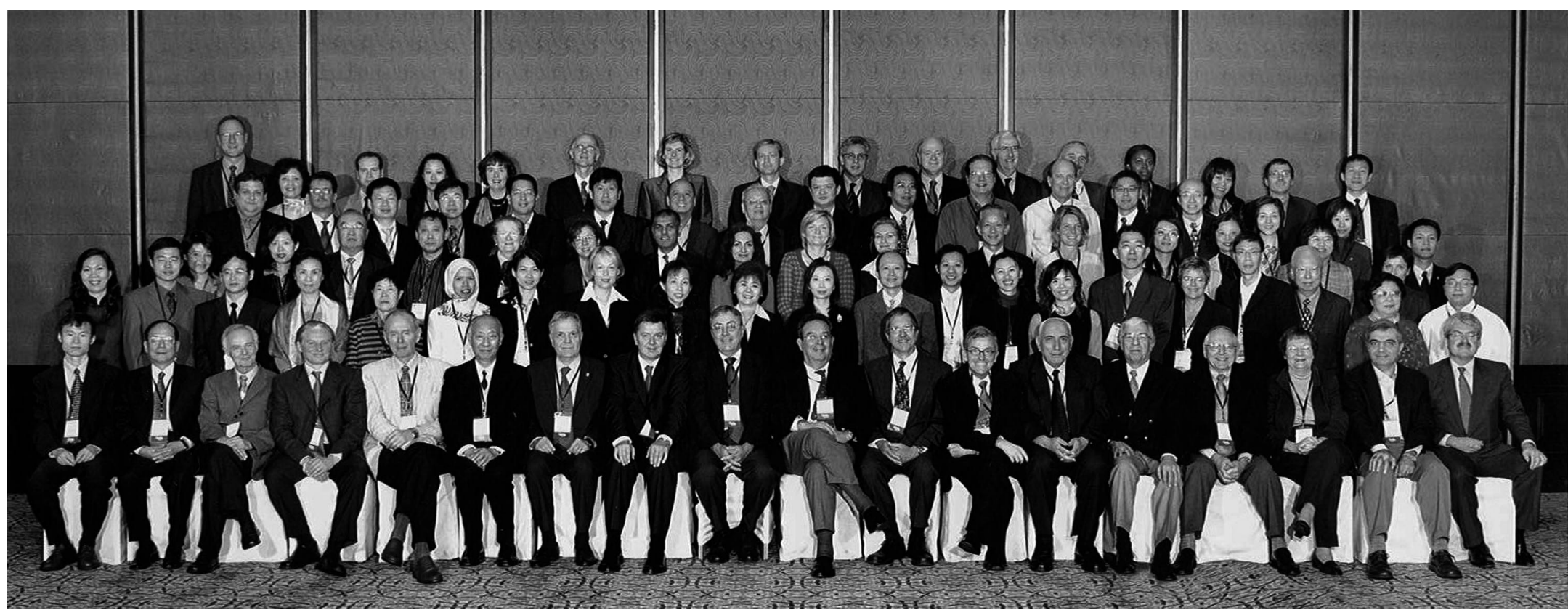

11th Nestlé Nutrition Workshop Clinical \& Performance Program

Hangzhou, China, October 30-November 3, 2005 



\section{Contributors}

\section{Chairpersons and Speakers}

\section{Prof. John P. Bantle}

Division of Endocrinology and Diabetes

Department of Medicine University of Minnesota 420 Delaware Street SE Minneapolis, MN 55455 USA

E-Mail bant1001@tc.umn.edu

\section{Prof. Jean-Louis Chiasson}

Research Center - CHUM (Hôtel Dieu) 3850 St. Urbain Street

Montréal, Qué. H2W 1T7

Canada

E-Mail jean.louis.chiasson@ umontreal.ca

\section{Dr. Herwig H. Ditschuneit}

Medizinische Universitätsklinik Universitätsklinikum Ulm

Robert-Koch-Strasse 8

DE-89081 Ulm

Germany

E-Mail herwig.ditschuneit@ medizin.uni-ulm.de

\section{Prof. John P. Foreyt}

Behavioral Medicine Research Center Baylor College of Medicine 6655 Travis Street, Suite 320 Houston, TX 77030 USA

E-Mail jforeyt@bcm.tmc.edu
Marion J. Franz, MS, RD, $C D E$

Nutrition Concepts by Franz, Inc.

6635 Limerick Drive

Minneapolis, MN 55439

USA

E-Mail marionfranz@aol.com

\section{Prof. Alain Golay}

Service of Therapeutic Education for Chronic Diseases Diabetes - Obesity

Department of Community

Medicine

University Hospital of Geneva

24, rue Micheli-du-Crest

CH-1211 Geneva 14

Switzerland

E-Mail alain.golay@hcuge.ch

\section{Dr. James O. Hill}

Center for Human Nutrition

University of Colorado

School of Medicine

Campus Box 263

Denver, CO 80262

USA

E-Mail james.hill@uchsc.edu

\section{Prof. Nicholas Katsilambros}

Laiko General Hospital

Agiou Thoma 17 Street (Goudi)

GR-11527 Athens

Greece

E-Mail laennec@techlink.gr 


\section{Prof. Cyril W.C. Kendall}

Department of Nutritional

Sciences

Faculty of Medicine

University of Toronto

Clinical Nutrition and Risk Factor

Modification Center

St. Michael's Hospital

Toronto, Ont. M5S 3E2

Canada

E-Mail cyril.kendall@utoronto.ca

\section{Prof. William C. Knowler}

Diabetes Epidemiology and Clinical Research Section

National Institute of Diabetes and

Digestive and Kidney Diseases

1550 E Indian School Road

Phoenix, AZ 85014

USA

E-Mail knowler@nih.gov

\section{Prof. Boyd E. Metzger}

Northwestern University

15-735 Tarry Building

303 East Chicago Avenue

Chicago, IL 60611

USA

E-Mail bem@northwestern.edu

\section{Dr. Arshag D. Mooradian}

Division of Endocrinology

Saint Louis University

1402 S. Grand Blvd

St. Louis, MO 63104

USA

E-Mailmooradad@slu.edu
Prof. Hans Peter Sauerwein

Department of Endocrinology and Metabolism

F5-170

Meibergdreef 9

NL-1105 AZ Amsterdam

The Netherlands

E-Mail h.p.sauerwein@amc.uva.nl

\section{Prof. Gérard Slama}

Department of Diabetes

Hôtel Dieu Hospital

1, place du Parvis Notre Dame

FR-75004 Paris

France

E-Mail gerard.slama@

htd.ap-hop-paris.fr

\section{Prof. Terence Wilkin}

Department of Medicine Postgraduate Medical School Level 7, Derriford Hospital Plymouth PL6 8DH UK

E-Mail terence.wilkin@ phnt.swest.nhs.uk

\section{Dr. Hailu Zhao}

Department of Medicine and Therapeutics

Prince of Wales Hospital

Ngan Shing Street 30-32

Shatin, Hong Kong, SAR

China

E-Mail zhaohailu@cuhk.edu.hk

\section{Moderators}

\section{Dr. Peter C.Y. Tong}

Prince of Wales Hospital

Shatin, Hong Kong, SAR

China

E-Mail ptong@cuhk.edu.kh

\section{Prof. Mingdao Chen}

Shanghai Institute of Endocrine and Metabolic Diseases

197 Ruijin Road II
Shanghai 200025

China

E-Mail mingdaochensh@yahoo.com

\section{Prof. Zuzhi Fu}

Medicine Sun Yet-Sen University

No. 135, Xin Gang Xi Road

Guangzhou 510275

China 


\section{Prof. Low-Thone Ho}

Taipei VHG: 201

Shih-Pai Road, Section 2

Taipei

Taiwan

E-Mail itho@vghtpe.gov.tw

\section{Prof. Hongding Xiang}

Department of Endocrine

Peking Union Medical College

Hospital

No. 1, Shuai Fu Yuan

Dongcheng District

Beijing 100730

China

E-Mail xianghd@vip.sohu.net

\section{Invited attendees}

Dr. Daniel Giannella Neto / Brazil

Prof. Catherine Field / Canada

Prof. Donglian Cai / China

Prof. Jialun Chen / China

Prof. Xiafei Chen / China

Prof. Zongyi Ding / China

Prof. Sheng Ge / China

Prof. Renming Hu / China

Prof. Linong Ji / China

Prof. Wiing Jia / China

Prof. Zhimin Liu / China

Prof. Rongli Qian / China

Prof. Jianqin Sun / China

Prof. Mengli Sun / China

Prof. Haoming Tian / China

Prof. Jianping Weng / China

Prof. Manying Xu / China

Prof. Huixia Yang / China

Prof Yongnian Yang / China

Prof. Demin Yu / China

Prof. Serge Halimi / France

Dr. Patrick Serog / France

Prof. Elisabeth Steinhagen-Thiessen /

Germany

Ms. King Chi, June Chan / Hong Kong
Mr. Yung Kind, David Chan / Hong Kong

Ms. Tsui Fun, Lornea Cheung / Hong Kong

Dr. Chun Chung Chow / Hong Kong

Ms. Wai Shan, Wendy Tam / Hong Kong

Dr. Johanes Casay Chandrawinata / Indonesia

Prof. Khalid Abdul Khadir / Malaysia

Dr. Francisco Lagrutta / Panama

Dr. Carlos Velarde / Panama

Dr. Roberto Mirasol / Philippines

Dr. Rosa Allyn Sy / Philippines

Dr. Saddah Eshki / Saudi Arabia

Dr. Chee Fang Sum / Singapore

Dr. Kaushik Ramaiya / South Africa

Dr. Gabriel Olveira / Spain

Prof. Lee-Ming Chuant / Taiwan

Dr. Chao-Hung Wang / Taiwan

Dr. Natapong Kosachunhaunun / Thailand

Dr. Apussanee Boonyavarakul / Thailand

Dr. Nattachet Plengvidhya / Thailand

Dr. Linda Wilkin / UK

\section{Nestlé Nutrition participants}

Mrs Penelope Small / Australia Dr. Olivier Ballevre / China Mrs. Bénédicte Sentenac / France Ms. Mandy Ma / Hong Kong

Mr. Satoru Okada / Japan

Ms. Jean Ang / Malaysia

Mrs. Amelita Valenzuela / Philippines

Ms. Ai-joo, Alicia Ng / Singapore

Mrs Patricia Anthony / Switzerland

Dr. Denis Barclay / Switzerland

Mr. Dominique Brassart / Switzerland
Dr. Jason Chieh Chou / Switzerland

Prof. Ferdinand Haschke / Switzerland

Dr. Natalia Leonova / Switzerland

Dr. Eduardo Schiffrin / Switzerland

Dr. Thomas Schweizer / Switzerland

Mr. Pierre Wuersch / Switzerland

Ms. Patricia Lee / Taiwan

Mr. Keith Colin-Thome / Thailand

Ms. Wirudchada Suttayakom /

Thailand

Ms. Fabienne Le Tadic / UK 
